\title{
Study on Social Cultural Adaptability of International Students in China under the Background of "the Belt and Road"
}

\author{
Bo Liu ${ }^{1, a}$ \\ ${ }^{1}$ Department of Foreign Languages, Qiqihar Medical University \\ No 333, Bukuibei Street, Jianhua District, Qiqihar of Heilongjiang Province, China \\ artkj2014II@foxmail.com
}

Keywords: The Belt and Road; International students in China; Socio-cultural adaptability

\begin{abstract}
The Socio-cultural adaptability of international students in China under the background of "the Belt and Road" is discussed, and the results found that the existing literature coverage on socio-cultural adaptability of international students in China is not sufficient yet. This paper analyzes the value system, cultural biases, national centrism, and the individual variations on cultural adaptability of international students in China, and proposes some advice to solve the problem.
\end{abstract}

\section{Introduction}

In 2013, Chinese President Xi Jinping put forward the significant initiative of "the Silk Road Economic Belt and Maritime Silk Road of 21st-Century" (henceforth "the Belt and Road") . "People-to-people bond", which is one of the "five points" of the initiative. And proposes the inheritance and promotion of the silk road spirit of friendly cooperation to extensively carry out cultural exchanges and academic interactions. Enlarging the number of students studying in each other's countries, and to carry out cooperative education. Human resources with professional expertise are necessary in interconnection of infrastructure, the cooperation of investment and trade or the accommodation of financing. The policy communication, popular communication, and even the establishment of politically mutual trust and "People-to-people bond" are all unable to be realized without talent and intellectual supports by higher education. That human resource training is of great significance in the implementation of "the Belt and Road". With the proposing of the "the Belt and Road", the number of students from countries on "the Belt and Road" has doubled[1].

The ministry of Education statistic 2015 recorded the number of students in China from the countries on "the Belt and Road", which is shown in Table 1. It can be seen that the number of students coming from the countries on "the Belt and Road" in recent years have been rising, which constitutes a sustained growth. In addition, the vice minister of ministry of education Tian Xuejun proposing "Promoting the People-to-people Bond along the Belt and Road" in a state council press conference in May 12, 2017. And the number of international students in China reached 207,746 by the end of 2016, which increased 13.6\% than last year, among which Thailand, India and Pakistan contributed most students [2,3]. 
Table 1 The development trend of foreign students coming to China from 65 countries and regions along the line "The Belt and Road Initiative".

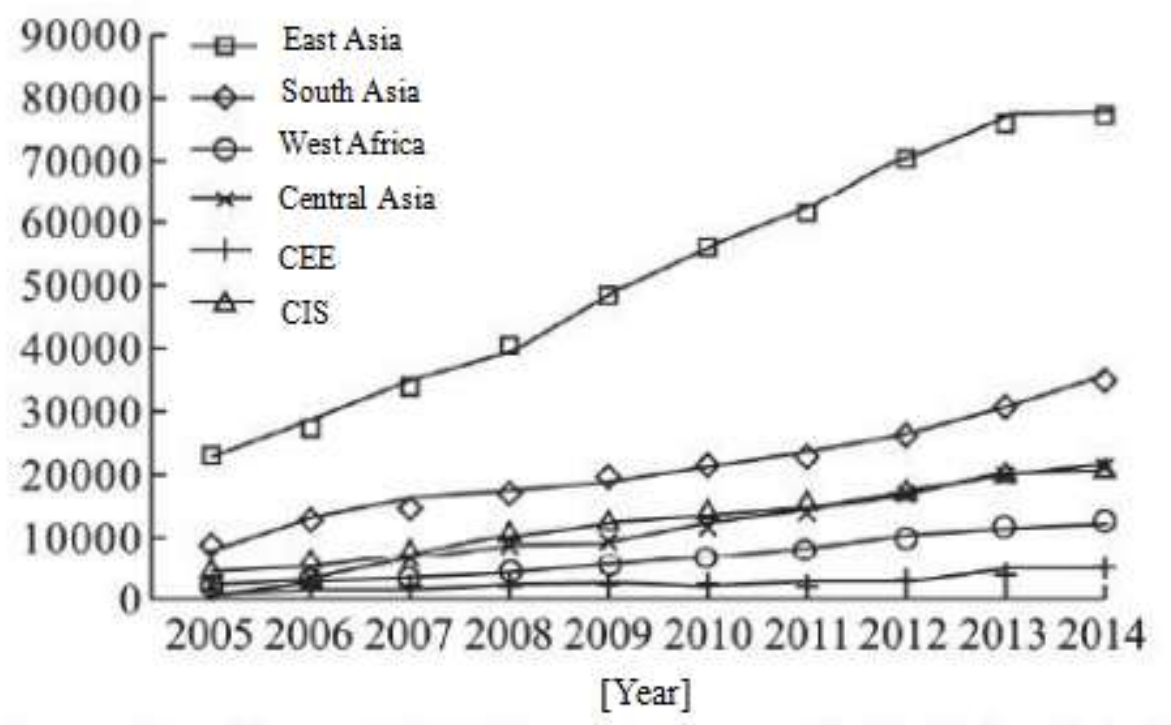

However, in addition to other "four tongs" of Chinese nomenclature (i.e., policy coordination, facilities connectivity, unimpeded trade and financial integration), the fifth tong, i.e., people-to-people bond, still progresses in a slower pace. And it is the social foundation of constructing the Belt and Road, which stresses communication and understanding of the people living in relevant countries and regions and it includes cultural and educational exchanges. The number of students coming to China from countries on "the Belt and Road" increases on a yearly basis, but their cultural adaption to Chinese society remains in problem. There are still many aspects of Chinese culture which have not been adapted and understood by them. It is mainly due to the differences in fundamental realities and cultural backgrounds between China and their own countries, and the differences are not conducive to mutual trust and understanding between us and them. In short, there is a question about socio-cultural adaptability of international students in China.

\section{Research, Analysis and Suggestions}

The Significance of a Cross-cultural Study on the Socio-Cultural Adaptability of International Students in China under the Background of "the Belt and Road". At present, the academic understanding to the question of cultural adaption is based on Ward, C, Kennedy, who proposed a two-dimensional division of psychological adaption and socio-cultural adaption. Psychological adaption is relevant to emotional reactions, such as mental health and life satisfaction during the process of cross-cultural contact. Socio-cultural adaption refers to the socialization process in which people learn to adapt the culture where they are living. The dimension of socio-cultural adaption in Chinese society can be subdivided into life adaptation, socio-ethical awareness adaptation, communication adaptation, social support adaption, service model adaption, social environment adaption and local lifestyle adaption[4]. Socio-cultural adaption is closely related to the local culture. So the socio-cultural adaption of international students in China is primarily relevant to value systems, cultural bias, ethnocentrism, and individual differences. Approaching to the question of socio-cultural adaption for foreigners in China through this perspective is thus of great theoretical and practical significance.

On the one hand, it is of practical significance. With the increasing international students in China, the resultant internationalization of Chinese society and culture is still less well-known besides the obvious economic benefits. And with the international students increasing, China as the host country needs to take some measures to sufficiently promote our socially and culturally of international 
influences. China used to stress the provisions of academic support and the guarantee of living standards to international students, while neglect the question of their psychological, emotional and spiritual adaptabilities. Which has a negative impact on them not only on their psychology, character, personality, academic fruitfulness, but also on the international image of China as the host country $[5,6]$.

Therefore, the research on the question about cross-cultural adaptation of international students can not only improve their personal socio-cultural adaptability, but also make them to be disseminators of great traditional Chinese culture, thus boosting the "Chinese Dream" out the world. Indeed, Chinese and people from countries on "the Belt and Road" are all used to their own traditional cultures. These cultures tend to inevitably conflict with each other when they meet. Through researches on the question of socio-cultural adaptability of international students, it is also conductive for us to understand cultures of other countries better, which can deepen our self-understanding, therefore gaining a better position to promote our own culture and integrate it into the world.[7].

On the one hand, it is of theoretical significance. "Cultural Adaptation" means "a conscious and preferential behavioral selection and adjustment when one transfers from the culture he used to live to another heterogeneous culture, based on his cultural cognition and emotional attachment between the two cultures." When faced with the pressure from unfamiliar cultural environment, the agent constantly made self-adjustment, gradually adapt to the new way of life, and eventually form an intercultural identity. There were research on the cross-cultural adaptation of international students earlier in China, but the early research is not systematic. Since the invention of the concept "culture shock" by United States cultural anthropologists Oberg in 1960, empirical methods had been gradually employed to explore this phenomenon and supplied details to it, thus a set of theoretical systems suitable for Western cultures are constructed [8]. But the outcomes drawn from Western culture cannot fully explain the cultural adaptation of international students in China. As world-renowned comparative pedagogist Altbach (1991) puts it, "the existing literature reflects a focus on the adaptions, coming-backs and related issue of international students in industrialized countries who themselves came from third-world countries, which reflects the concerns and interests of OECD countries, but they constitute just a fraction of all international student[9]. Therefore, despite great progress in establishing theoretical foundations for cross-cultural adaptation of international students, these researches still have limitations. Furthermore, these researches has only studied the subjective feelings of international students, which is less satisfactory, and still less researches were devoted to how to cope with their discomfort in another country[10].

Therefore, this research can provide foundations for the general cultural adaptability of international students, and provide basic data and foundations for governments and universities to improve their socio-cultural adaptability on the cultural adaptability of international students[5,11].

The Problems of Socio-Cultural Adaptality of International Students in China under a Cross-Cultural Context of "the Belt and Road". China provided 10,000 government scholarship for the countries on "the Belt and Road" each year to encourage international students study and communicate in China. The state has promulgated relevant policies to administrate the education of international students. Each university based on their own relevant policies, actively formulated a series of measures, which aimed at improve the quality of international students' training and to improve their ability of intercultural communication ability.

Qiqihar Medical University, with its psychiatry as one of First-Class Discipline with Distinctive Features at the national level and clinical medicine, psychiatry, pharmacy and preventive medicine as Key Disciplines of provincial level, which has many achievements that can be transformed into new industries promoted exactly by "the Belt and Road" and is also adapted to industrial upgrading of China. At present the University has established co-operations with many universities abroad, to explore the ways of training human resources of international mentality. But what kind of international human resources can meet the requirements of the Belt and Road initiative and how they are to be trained remains a question for us to answer. The problem especially worth to consider is that the socio-cultural adaptability of international students in China. Or else no success can be achieved in this subject. 
Because the profoundness and uniqueness of Chinese culture which has a history of 5,000 years, multiple problems in the socio-cultural adaptability of international students in China have been manifested, in which the following four are mostly prominent.

(1) Difference in Value System. This is the most prominent in these problems. Chinese people stress on collectivism, respect of tradition, keep obedient to power and authority, and practice of the Golden Mean. It is difficult for international students to endorse every aspect of Chinese cultural value system. Difference in value system can directly lead to culture shock and maladaptation. Many international students in China were thought that collectivism in Chinese culture makes people unconsciously put collective interests above their own, and individual's needs and goals are subordinate to the collective's needs, and individuals always keep ready to sacrifice themselves for the sake of the collective at any time. At the result, individuals are prone to give up their own thoughts and align their actions with the collective's goals. While they abandon one's own pursuits and subject themselves to higher political and moral authority, which limits their personal independence [12].

Collectivist mentality has made China a society of Guanxi (which emphasized personal connections or relationships as the bases of better engaging in social affairs). There are a lot of relationships as complicated as kinship, lineage relationship, countrymen relationship, as well as neighborhood relationship, classmates relationship, coworkers relationship, comrades in arms relationship and so on. The whole national identity is made out of these kinds of relationships. Chinese people would like to put themselves in these relationships and consider themselves as a member of the groups connected by these relationships. That's why Chinese society is seen as a "Guanxi society" and "human feeling society". In social occasions, people are busy dealing with various kinds of relationships and maintaining all kinds of human feelings, thus ignore the importance of personal struggle and defense of individual rights.

Collectivist mentality has also made China a society stressing on "face-saving". People in Guanxi are prone to maintain their good reputation and image, so they constantly adjust their behavior to conform the value system of the collective, that resulting in behaviors of "overly stressing on saving face", thus constructs a society of "face-saving". Thinking, creativity and struggle are no longer people's primary concerns, instead ways of face-saving become their primary. Individuals' faces must be saved when they are members of whatever collectives, and smaller collectives' "faces" must also be saved when they are a part of whatever larger collectives.

The Chinese society as a society of Guanxi and a society of face-saving, which is the manifestation of China's social collectivism, also of both merits and defects. But as a value system ingrained in Chinese mentality, Chinese people persist in both "societies", which have constructed some unwritten social norms, and known by Chinese as "unspoken rules", and which are not been quickly adapted by international students from other countries.

(2) Cultural Biases. Before one's sufficient acquaintance with the certain culture, one usually has prejudice toward that culture for insufficient understanding of it. For example, several years ago many international students believed that China was closed and backward, where women are inferior to men, and performance in science research is not good. They also believed that Chinese people tend to be selfish and without public virtue, be oversensitive, always jump the queue, be sloppy, conservative, shy, sleek and so on. The root of the prejudice is that the lack of the understanding of Chinese culture as well as insufficient exportation of culture by China. Chinese culture is both extensive and profound. It has a long history of five thousand years and of deep cultural details. In the past, we didn't export our culture to a significant extent, and had poor cultural communications with other countries, which results in many biased from international students for insufficient and inaccurate information they received. These cultural biases have also resulted in their maladaption to Chinese culture.

(3) Ethnocentrism. Ethnocentrism is a belief that one's native culture superior to other cultures. People usually feel prideful or even conceited of the collectives they are a member of. This ethnocentrism makes them believe that their own ethnic groups are superior, extremely important and wonderful. Meanwhile they believe that other ethnic groups are somehow related to their own ethnic culture, especially in terms of language, behavior, mores, and religion, thus despise other ethnic 
groups. This ethnocentrism can define a unique cultural identity of each ethnic group. Coming from foreign countries, international students become more consciously aware of their own national and ethnic identities when facing different ethnic groups in a different country. This awareness can increases the sensitivity of patriotism and nationalism, but it hinders the appreciation of the new culture and broadening their vision.

(4) Individual Variation in Cultural Adaptation. The personalities, cognitive levels, skills and language abilities of international students in China all influence their cross-cultural adaptation. Craig Storti points out that in cross-cultural communication, the agent is expecting other persons to think and behave as he himself does, but in reality this is not usually the case. Thus results in cultural conflict, and makes the agent unable to understand and feel frustrated, finally fail to make a cross-cultural communication [13,14,15].

(5) Language Problems. Language is the primary element of communication for international students. At present, most universities and class sessions in China use Chinese as the teaching language. Before an international student able to speak Chinese, his teachers usually talk to them and teach the course in English. International students will study Chinese in one year before their learning. However, Chinese characters and words are numerous and their meanings are rich and complex, most international students cannot greatly improve their Chinese proficiency in a relatively short time. They can only do some basic daily communication while unable to learn their majors via Chinese language. Some students are unable to keep the pace of teaching, nor can they effectively communicate with the teachers. Living in a foreign country, international students would like to get closer to each other, and their dormitories are usually in the same place, so they even have less chance to communicate with Chinese students and teachers, which have less ideal environment to use Chinese they have learned. Furthermore, mother tongues of many international students are not English either. Their English proficiency varies a lot. But Chinese teachers usually cannot teach them via their own languages. [16,17].

(6) Other Factors. Social-supports are one of the factors that influence the socio-cultural adaptability of international students. Some study has shown that the most adapted international students are not the Japanese nationality, whose culture was most similar to Chinese culture. Rather, students from Europe and the United States, whose cultures are more dissimilar from Chinese, are more adapted to Chinese culture than Japanese students. This result based on the differences in social-supports. In China, the international students who have lessons together with Chinese students usually have good and relatively positive impressions to Chinese. As a result, their adaptability to Chinese cultural is the best, therefore receive best social supports and have the greatest enthusiasm to participate in social and cultural in China. [8].This results in some positive preconceptions of Chinese and makes the foreign students readily accepted by Chinese classmates. In addition, the political and economic status of the students native country, the economic and trade relations of their countries to China, diplomatic relations to China, and Chinese students' understanding the cultures of their native countries all affect the socio-cultural adaptability of international students in China. For example, there is discrepant management between Chinese students and foreign students. China attaches great importance to care-for-welfare management of international students because of their foreigner status, but this concept boosts as well as hinders their participation in Chinese society when they get educated in China. China always provides as good comfortable living conditions and service facilities as possible to international students, and respected their living habits and religious practices. But this kind of "affirmative action" blocks them from participating in Chinese culture life with Chinese students, thus contributes to their socio-cultural maladaption [18,19].

Measures and Suggestions to Solve the Socio-Cultural Adaptability of International Students in China Coming from Countries on "the Belt and Road". Through our survey and analysis of socio-cultural adaptability of international students in China, there are four stages in their cross-cultures adaptation, which are in turn: curiosity about the new culture, challenges and frustrations in the new culture, self-adjustment to the new culture, adaption to the new culture (the appreciation of new culture). Therefore, international students need to be prepared in every stage to adapt cross-cultural communications. Before coming to China, they should understand Chinese 
culture sufficiently and adjust their expectations and degrees of appreciation of this culture, to psychologically prepare for the cross-cultural adaption. After coming to China, they should be provided with training for cross-cultural adaption to consciously aware of cultural differences. They should learn some concrete skills of intercultural communication and can practice this skill in real social settings. If they are frustrated in communication because of cultural difference, they should be aided with effective methods and measured to alleviate the frustration.

Thus we propose following advice to universities in China to improve the adaptability of international students:

First, to improve language training. Language is the key to interpersonal communication, lack of language proficiency will lead to inability to communicate. Universities need to set up more courses and lectures in Chinese language, culture and literature, thus promoting the Chinese proficiency of international students in China.

Second, to carry out training on interactive communication under intercultural settings. Universities can create more opportunities for international students to interact with Chinese students, increasing the time of foreign students' exposure to Chinese students.

Third, to conduct policy consultation and information exchange through multiple channels. This would encourage international students to participate in China's social and cultural life and give them the opportunity to express their opinions about China's educational system and management through many channels. The international students come from a variety of countries, and they have knowledge of a wide range of subjects. They can give a lot of inspirational suggestions about every aspect of China's development, which can be a valuable information resource to be further exploring. To cultivate their affinity to China and comfort in Chinese culture, we can provide students with a particular culture tutor, and they can get help from this particular teacher when necessary. In one word, we should make international students as comfortable as they lived in their own countries, thus they can have more positive impressions on Chinese culture.

Fourth, we should guide students to adjust themselves to be adapted for Chinese culture. In order to improve their self-adjustment ability when they are experiencing culture shock, we should consciously provide guidelines during the process of their self-adjustments.

Finally, to gradually switch to the convergence management model. Under this model, contact between international students and Chinese students and Chinese society will expand. For example, to implement home-stay project with the assistance of students' union, thus more international students can live in Chinese families, which helps them to improve the understanding of the Chinese people.

\section{Conclusion}

The key of good relations between states lies in the affinity between their people, which is a result of interactions between cultures, which in turn stems from understanding of languages of each other. Language proficiency is the result of training and education [20]. It becomes more and more important for of international students education to cultivate the socio-cultural adaptability of international students in China. Cultivating a lot of foreign youth who appreciate Chinese culture has a crucial and undeniable role to boost the success of "the Belt and Road" initiative.

\section{Acknowledgement}

This work was supported by the Humanities and Social Sciences Research Project of Education Department of Heilongjiang Province. The project number 2016-KYYWF-0891.

\section{References}

[1] C.J. Ying: Journal of Lianyungang Technical College, Vol. 29 (2016) No.3, p.57-60. (In Chinese).

[2] W.H. Cheng: Higher Agricultural Education, (2017) No.3, p.88-93. (In Chinese) 
[3] Y.H. Liu: . Heilongiiang Researches on Higher Education, (2016) No.3, p.10-14. (In Chinese).

[4] Ward C and Kennedy A: International Journal of Intercultural Relations, Vol.16 (1992) No.2, p.175-194.

[5] M. Wan: Modern Educational Science, (2008) No.6, p.19-21. (In Chinese).

[6] Ward C and Kennedy A: International Journal of Intercultural Relations, (1992) No.23, p.175-194 and p.659-677.

[7] Y.Q. Zhang: Education in Asia Pacific, (2016) No.32, p.285-286. (In Chinese).

[8] J.H. Yang: A Study of Intercultural Adaptation of International Students Studying in China (Ph.D., East China Normal University, China 2005) , p.11-14, 34-37. (In Chinese).

[9] P.G Altbach: Higher Education, Vol.21 (1991) No.3 , p.305-323.

[10] X. Chen: The study of "the Belt and Road" national overseas students cultural distance, cultural strategy and cultural adaptation (Master, Hangzhou Normal University, China 2016), p.11-19. (In Chinese).

[11]D.J. Li: Journal of Yunnan Normal University (Philosophy and Social Sciences), Vol.39 (2007) No.5, p.49-51. (In Chinese).

[12] G.M. Yu and Y.Q. Wang: Journal of Dalian Institute of education, Vol.20 (2004) No.3, p.26-28. (In Chinese).

[13] Y.Q. Li and Z.K. Yu: Journal of Chongqing University of Science and Technology (Social Sciences Edition), (2011) No.12, p.196-197. (In Chinese).

[14] W.Z. Hu: Introduction to intercultural communication (Foreign Language Teaching and Research Press, China 2010). p.94-99. (In Chinese).

[15] Y.S. Shi: Foreign Language World (General Serial No.165), (2014) No.6, p.79-87. (In Chinese).

[16] G.S. Yang and A.B.Yu: A Localization Research of Chinese Psychology and Behavior (China Renmin University Press, China 2004). p.92-114. (In Chinese).

[17] L.P. Lin: The Investigation and Study of Foreign Students' Language Use and Language Attitude of Chinese (Master, Huaqiao University, China 2016), p.50-51. (In Chinese).

[18] Rachel A. Smith, Nigar G. Khawaja: International Journal of Intercultural Relations, (2011) No.35, p.699-713.

[19] Townsend, P. and Poh, H: Journal of Marketing for Higher Education, Vol.2 (2008) No.18, p.240-263.

[20] H.D. Wu: Education in Asia Pacific, (2016) No.10, p.250. (In Chinese). 